Konrad ZAWADZKI

(Theologische Fakultät Trier)

\title{
DIE ANFÄNGE DES „ANATHEMA” IN DER URKIRCHE*
}

\section{ANHALTSPUNKTE FÜR DAS ANATHEM IM NEUEN TESTAMENT}

Will man nun dem Problem der kirchlichen Anathematisierungen systematisch sowie chronologisch nachgehen, erscheint es unerlässlich, sich zunächst die Frage zu stellen, ob eine solche Praxis eine Basis in den neutestamentlichen Schriften hat. Da diese Schriften im Raum der Urkirche entstanden sind, stellen sie eine durchaus bedeutende Quelle für die Erkenntnis des theologischen Geistes der ersten christlichen Jahrzehnte dar. Sollte sich herausstellen, dass sich das Anathem, auch nur spurenweise, im Neuen Testament findet, wäre dies sehr wichtig für die weitere Analyse des Problems. Die alte Kirche wächst nämlich unmittelbar aus der neutestamentlichen Zeit heraus und ist deshalb durch deren Geist bestimmt.

Walter Doskocil präsentiert in seinem Buch eine Zusammenstellung von Perikopen, die die neutestamentliche Praxis des Kirchenbanns nachweisen sollen ${ }^{1}$. Er beginnt diese Präsentation mit den entsprechenden Stellen aus den Evangelien, geht zur Briefliteratur über und endet seine Darstellung mit der Offenbarung des Johannes. In all den genannten Teilen des Neuen Testaments sucht Doskocil Ansätze für den Kirchenbann und glaubt, sie finden zu können. Er lässt allerdings dem Begriff des Kirchenbanns eine sehr breite Bedeutung zukommen und bezieht ihn sowohl auf die Sünder als auch auf die Häretiker und diejenigen, die gegen die kirchliche Disziplin verstoßen. Deshalb zitiert er alle neutestamentlichen Stellen, die über Ausstoßung eines Kirchengliedes aus der Gemeinschaft der Gläubigen ${ }^{2}$ berichten. In diesem Zusammenhang erhebt sich allerdings die grundsätzliche Frage, ob man das Problem so undifferenziert betrachten kann. Ist das neutestamentliche Anathem tatsächlich mit dem Begriff des Kirchenbanns gleichbedeutend? Gibt es hier keine Besonderheiten, die das

\footnotetext{
* Der erste Teil des Aufsatzes ist in VoxP 28 (2008) t. 52/2, 1323-2334 erschienen.

${ }^{1}$ Vgl. W. Doskocil, Der Bann in der Urkirche, München 1958, 26-114.

${ }^{2}$ So definiert Doskocil (unter Berufung auf Eichmann-Mörsdorf) den Begriff des Kirchenbanns, siehe Doskocil, Der Bann in der Urkirche, S. 3.
} 
neutestamentliche Anathem von den anderen Ausschließungssanktionen der Kirche unterscheiden würden?

1. Das Anathem bei Paulus. Bei der Analyse der neutestamentlichen Anathemproblematik soll der Blick vor allem auf die Schriften des Paulus gelenkt werden, die angesichts des frühen Entstehungsdatums in erster Linie behandelt werden sollen. Außer der Chronologie gibt es aber noch einen Grund, weshalb diese Schriften im Zusammenhang mit meiner Untersuchung eine besondere Beachtung verdienen. Bei Paulus finden sich nämlich die Stellen im Neuen Testament, an denen das Wort $\alpha$ vó $\theta \varepsilon \mu \alpha$ in dieser Form am häufigsten vorkommt. Man kann demzufolge mit einiger Sicherheit sagen, dass dieser neutestamentliche Begriff vorwiegend zum paulinischen Schriftgut gehört ${ }^{3}$. Deshalb muss zuerst überprüft werden, wie Paulus diesen Terminus verstanden haben will und welche praktische Bedeutung er seinem ơ $\nu \alpha ́ \theta \varepsilon \varepsilon \mu \alpha$ beimisst. Es ist in diesem Zusammenhang auf die folgenden Perikopen einzugehen: Röm 9, 3; 1 Kor 12, 3; 1 Kor 16, 22; Gal 1, 8f.

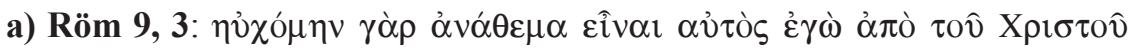

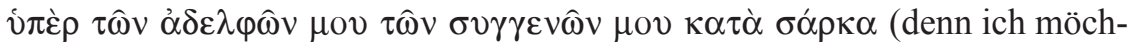
te selbst ,anathema” sein, weit weg von Christus, zugunsten meiner Brüder, meiner Verwandten nach dem Fleisch).

Der Kontext dieser Stelle macht deutlich, dass sich Paulus mit den Juden, die er hier als seine Brüder nennt, eng verbunden fühlt. Diese Verbundenheit betont vor allem die Tatsache, dass der Apostel ,anathema” zu sein wünschte, wenn er dadurch den Israeliten bei der Annahme des Evangeliums helfen könnte. Die semantische Analyse des oben dargestellten Zitats verdeutlicht, wie ernsthaft und zugleich drastisch dieser Wunsch des Paulus den Lesern

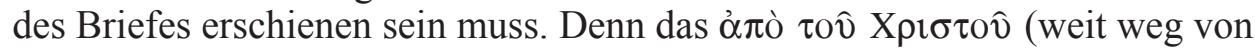
Christus) verweist unmittelbar auf den Sinn des paulinischen Terminus ,,anathema" und stellt klar, dass Paulus um seiner Brüder willen zu etwas werden möchte, was mit Christus überhaupt nichts zu tun hat, was für Christus völlig fremd ist, was sich außerhalb von Christus befindet ${ }^{4}$. Zieht man in diesem Zusammenhang die Tatsache in Betracht, dass Christus für Paulus der Erlöser ist ${ }^{5}$, so muss man feststellen, dass der Apostel, der hier ,,anathema” sein will, nichts anderes als Fluch bzw. Verdammnis wünscht. Denn was kann, nach der Auffassung des Paulus, außerhalb von Christus, dem Heiland, Gutes sein? Aus diesem Grund könnte man den Satz ins Deutsche folgendermaßen übertragen: ,ich möchte verdammt/verflucht sein, ich möchte mit Christus nichts zu tun haben, wenn dies nur meinen Brüdern, meinen Verwandten nach dem

\footnotetext{
${ }^{3}$ Vgl. ibidem, S. 54.

${ }^{4}$ Vgl. H. Schlier, Der Römerbrief, Freiburg - Basel - Wien 1977, 286.

${ }^{5}$ Vgl. Röm 5, 10.
} 
Fleisch hälfe". Eine solche Übersetzung macht deutlich, dass der paulinische Gebrauch von ỏvó $\theta \varepsilon \mu \alpha$,auf der Linie der LXX liegt”. Es bezeichnet einen Gegenstand des Fluches und entspricht deshalb inhaltlich dem hebräischen חרם . Das Anathem bedeutet demzufolge, ,das äußerste Leiden preisgegebener Verlorenheit"', die schrecklichste Strafe, die man sich vorstellen kann.

Die Perikope aus dem Römerbrief $(9,3)$ präzisiert demzufolge eindeutig die Bedeutung des paulinischen Anathems und bezeugt, dass es einerseits ohne Zweifel an die jüdischen Vorstellungen knüpft, andererseits aber auf der Linie des christlichen Verständnisses liegt. Denn nur an der Zugehörigkeit zu Christus kann man, nach paulinischer Auffassung, das Heil und die Erlösung messen. Alles, was sich außerhalb von Christus befindet, gehört zum Bereich des Anathems und ist ipso facto verflucht, verdorben und verdammt.

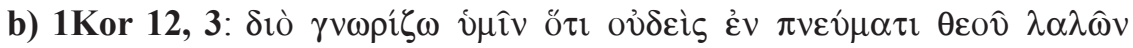

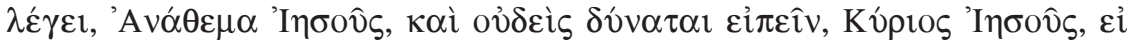

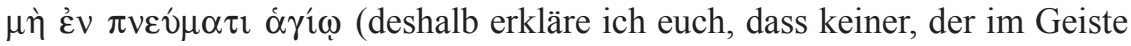
Gottes spricht, sagt: „Anathema” Jesus, und keiner kann sprechen: Der Herr Jesus, außer im Heiligen Geiste).

Der Vers gibt auf eine unmissverständliche Weise die Kriterien zur Unterscheidung echter charismatischer Begabungen $a^{8}$. Wer Jesus ,anathema" nennt, stammt nicht von Gott; wer Jesus als den Herrn bezeichnet, spricht im Heiligen Geiste. In diesem Zusammenhang erhebt sich die Frage, von wem konkret diejenigen kommen, die Jesus als ,anathema” bezeichnen. Die neusten Kommentare zum Neuen Testament, die sich mit der Stelle befassen, gehen auf dieses Problem gar nicht ein. Paulus scheint auf den ersten Blick, ebenso wenig an dieser Frage interessiert zu sein. Betrachtet man aber den zitierten Vers etwas genauer, so stellt man fest, dass der Apostel hier eindeutig mit einer Antithese arbeitet. Diese Antithese bilden mit Sicherheit die Begriffe: kúpıs (Herr) und $\alpha v^{\prime} \alpha \dot{\theta \varepsilon} \mu \alpha$ (Fluch) dar. Möchte man jetzt die Tatsache in Betracht ziehen, dass die Aussage Herr Jesus kein verbales Bekenntnis bedeutet, sondern eine die Existenz des Menschen bestimmende Formel zum Ausdruck bringt ${ }^{9}$, so muss es sich bei der Wendung Anathema Jesus um das Gleiche handeln. Der Unterschied zwischen den beiden Formulierungen beruht jedoch darauf, dass die erste eine positive und durchaus freundliche Einstellung zu Jesus bedeutet, während die zweite das Gegenteil signalisiert und offenbar auf eine negative und feindliche Verhaltensweise gegenüber dem Herrn hinweist.

${ }^{6}$ J. Behm, ỏvó $\theta \varepsilon \mu \alpha$, TWNT I, Stuttgart 1966, 356.

${ }^{7}$ E. Lohse, Der Brief an die Römer, Göttingen 2003, 266.

${ }^{8}$ Schrage macht hier darauf aufmerksam, dass sich die von Paulus präsentierten Kriterien zur Unterscheidung der Geister nicht auf ein bloß verbales Lippenbekenntnis beziehen, sondern auf eine öffentliche und verpflichtende Anerkennung (Leugnung) des Herrn im gesamten Leben, vgl. W. Schrage, Der erste Brief an die Korinther, Zürich - Düsseldorf 1999, 122-123.

${ }^{9}$ Vgl. ibidem. 
Diese gegnerische Position gegenüber Christus kann freilich auf den Geist Gottes nicht zurückgehen. Sie muss vielmehr einen anderen Ursprung haben, der grundsätzlich mit Gott nichts zu tun hat und sogar gegen ihn ausgerichtet ist. So kann man den Schluss ziehen, dass derjenige, der Jesus verflucht, unter dem Einfluss eines antigöttlichen Geistes steht. Daraus ergibt sich, dass der Versuch, das Anathem auf Jesus zu beziehen, eigentlich dämonischen Charakter hat und auf eine diabolische Besessenheit zurückzuführen ist ${ }^{10}$. Eine solche Interpretation macht deutlich, dass ,,anathema" nicht irgendeinen auBergöttlichen Bereich charakterisiert, einen Bereich, der mit Christus nichts zu tun hat, sondern den Bereich, der sensu stricto teuflischen Ursprungs ist. Diese Präzisierung des Begriffs scheint, noch mehr Licht auf die Bedeutung des paulinischen Anathems zu werfen. „Anathema” bezieht sich demzufolge auf einen zu verfluchenden Gegenstand deshalb, weil dieser Gegenstand dem Satan angehört und von ihm seinen Anfang nimmt. Aus diesem Grund kann derjenige, der Jesus mit dem Teufel in Verbindung bringt, indem er den Herrn mit dem

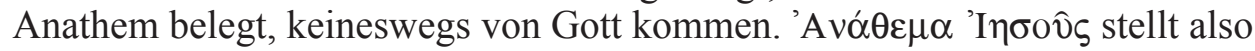
einen äußersten Widerspruch dar ${ }^{11}$ und verrät die teuflischen Absichten dessen, der eine solche Aussage zum Ausdruck bringt. „Der Wirkungsbereich des (Heiligen) Geistes fällt mit dem Herrschaftsbereich des Herrn zusammen"12. Deshalb ist es unmöglich, dass der Geist Gottes den Menschen dazu treibt, antichristliche Sprüche zu verbreiten.

Die Verknüpfung des Anathems mit dem dämonischen Bereich erscheint mir als ein wichtiger Hinweis auf die Lösung der Frage, weshalb das Anathematisierte nach dem jüdischen Verständnis der Vernichtung durch Gott preisgegeben wird ${ }^{13}$. Denn alles, was Gott und seinem Willen entgegensteht, ist zum Scheitern und Niedergang verurteilt. Gott wird nämlich all seine Gegner endgültig besiegen ${ }^{14}$ und damit seine große Macht zeigen. Eine ähnliche Vorstellung, die an die jüdische Überzeugung vom definitiven Untergang alles Bösen knüpft, präsentiert auch Paulus. Er glaubt fest daran, dass Christus jeden Gegner und Feind überwindet ${ }^{15}$. Aus diesem Grunde wird ebenso die ganze Sphäre des Anathematisierten der Vernichtung durch Gott anheimfallen, weil sie mit den antigöttlichen, teuflischen Kräften in enger Verbindung steht. Das jüdisch-paulinische Anathem betrifft demzufolge einen Bereich, der von vornherein zur Destruktion verurteilt ist.

${ }^{10}$ Vgl. H. Lietzmann, An die Korinther I/II, Tübingen 19494, 60 (zitiert nach: Doskocil, Der Bann in der Urkirche, S. 55).

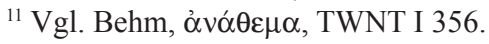

${ }^{12}$ Die Formulierung stammt von J. Vos, Das Rätsel von 1Kor 12, 1-3, NT 35 (1993) 259 (zitiert nach: A. Lindemann, Der Erste Korintherbrief, Stuttgart 2000, 265).

${ }^{13} \mathrm{Vgl}$. Behm, óvó $\theta \varepsilon \mu \alpha$, TWNT I 356.

${ }^{14}$ Vgl. Jes 59, 15b-20.

${ }^{15}$ Vgl. 1Kor 15, 24. 


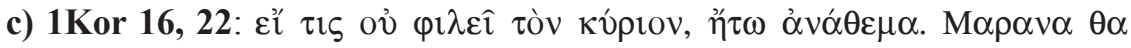
(wenn jemand den Herrn nicht liebt, sei er anathema. Marana tha).

Im Gegensatz zu den ersten beiden von mir behandelten Versen, die den Charakter und Sinn des paulinischen Anathems näher bestimmen ließen, verweist die gerade zitierte Stelle aus 1Kor 16, 22 vielmehr auf den Personenkreis, den das Anathem trifft. Anathematisiert werden demzufolge diejenigen, die den Herrn Jesus Christus nicht lieben. In diesem Zusammenhang stellt sich allerdings die prinzipielle Frage nach der Identität derer, die keine Liebe zum Herrn haben. Das griechische indefinite Pronomen $\tau i s$ (jemand, einer) verrät leider nicht allzu viel und hat eher eine allgemeine Bedeutung ${ }^{16}$. Will man aber dennoch dem Problem nachgehen, wen das paulinische Anathem in dieser Perikope betrifft, muss man die paulinische Wendung o кúprov (...den Herrn nicht liebt) genauer analysieren, weil sie den Charakter der hier Anathematisierten zum Ausdruck bringt. Es gibt in der Forschung zwei Thesen, die diese Formulierung auszulegen versuchen. Die erste von ihnen stellt diejenigen, die den „кúproৎ” nicht lieben, auf die gleiche Stufe mit denen, die seine Gebote nicht halten ${ }^{17}$. Dieser Auslegung zufolge wären alle Sünder von Paulus anathematisiert, da sie durch zahlreiche Verstöße gegen die göttlichen Gebote eindeutig zeigen, dass sie den Herrn nicht lieben. Die zweite These versteht das ov̉ $\varphi \imath \lambda \varepsilon \hat{\imath}$ (nicht liebt) etwas anders und verweist darauf, dass die paulinische Formulierung „,nicht lieben” mit „hassen” gleichbedeutend sein sollte ${ }^{18}$. Aus einer solchen Interpretation ergibt sich, dass das in der Perikope verwendete Anathem diejenigen trifft, die nicht nur sündigen. Das Verb „hassen” setzt nämlich eine aktive Verhaltensweise voraus, die sich prinzipiell und programmatisch gegen das Objekt des Hasses richtet. Dieser Sinndeutung zufolge würde sich das Anathem auf die Menschen beziehen, die Jesus bewusst und mit aller Kraft beseitigen wollen. Es handelt sich hier also in erster Linie nicht um diejenigen, die die Gebote des Herrn nicht halten wollen bzw. können, sondern vielmehr um diejenigen, die sich aktiv und systematisch gegen den Herrn, seine Lehre und seinen Geist einsetzen. Diese zweite Interpretation erscheint mir zutreffender und richtiger als die erste. Es wurde nämlich aufgrund der Perikopen aus Röm 9, 3 und 1Kor 12, 3 eindeutig nachgewiesen, dass das paulinische Anathem einen Bereich betrifft, der teuflischen Ursprungs ist, dem Satan angehört und deshalb mit Christus nichts zu tun hat. Will man diese Sinndeutung auf unsere Stelle übertragen, so muss man feststellen, dass derjenige, der den Herrn nicht liebt, als verflucht, d.h. als vol1ständig von Gott getrennt, betrachtet werden muss. Er soll ,anathema” sein; er gehört zum Teufel und wird von Gott vernichtet. Kann der Sünder damit ge-

${ }^{16}$ Siehe die Diskussion darüber in: Lindemann, Der erste Korintherbrief, S. 388.

${ }^{17}$ Diese Auffassung vertreten E.B. Allo, Saint Paul, Première Épitre aux Corinthiens, Paris 1934, 468-469; Doskocil, Der Bann in der Urkirche, S. 56.

${ }^{18}$ Vgl. Lindemann, Der erste Korintherbrief, S. 388. 
meint sein? Eine solche Interpretation würde der Theologie des Paulus völlig widersprechen. Er betont nämlich immer wieder, dass Christus die Rettung, nicht die Vernichtung des Sünders will ${ }^{19}$. Es wäre demzufolge unsinnig, wenn der Apostel sein Anathem, das eindeutig mit der alttestamentlichen Idee der Vernichtung durch Gott verbunden ist, gegen die Sünder richtete. Aus diesem Grunde muss man die These annehmen, dass derjenige, der den Herrn nicht liebt, ihn in Wahrheit also hasst. Das Anathem betrifft demzufolge denjenigen, der eine grundsätzliche Gegeneinstellung zu Christus präsentiert, den Herrn mit aller Kraft beseitigen will und deshalb vielmehr mit dem Teufel als mit Jesus verbunden ist. Eine solche Präzisierung des Personenkreises, auf den sich das paulinische ,anathema" beziehen soll, entspricht in jeder Hinsicht dem Sinn und dem Charakter des Begriffs.

Zusammenfassend lässt sich sagen, dass der Einsatz des Anathems in 1Kor 16, 22 eine bewusste und systematisch orientierte Aktivität voraussetzt, die auf eine programmatische Bekämpfung Christi ausgerichtet ist. Eine solche Aktivität lässt sich keineswegs mit der Sündhaftigkeit gleichsetzen, die oft der Ausdruck der menschlichen Schwäche, nicht eines wirklichen Kampfes mit Gott, zu sein scheint. Nur derjenige, der Jesus hasst, ist in der Lage, mit seinem ganzen Dasein dem Herrn ein „Nein” zu sagen und alle seine intellektuellen sowie physischen Kräfte für dieses „Nein” einzusetzen, um Christus zu vernichten. Der Hass zielt nämlich immer auf die Destruktion seines Objektes. Deshalb wird derjenige, der eine solche Einstellung gegenüber Jesus präsentiert, von Paulus mit einem Anathem belegt, da sein Handeln zutiefst diabolischen Charakter aufweist. Das am Ende des Verses stehende marana tha (unser Herr, komm!) ${ }^{20}$ verstärkt noch dieses Anathem. Der Herr ist derjenige, der durch sein Kommen den ausgesprochenen Fluch vollzieht ${ }^{21}$.

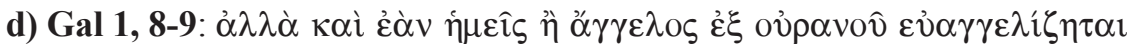

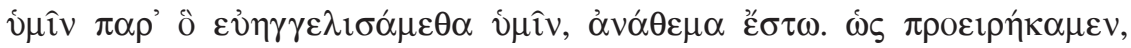

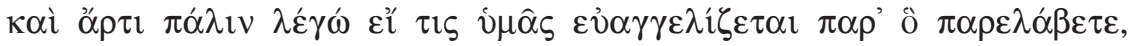
$\grave{\alpha} v \alpha \dot{\theta} \theta \varepsilon \mu \alpha$ ह̌ $\sigma \tau \omega$ (aber auch wenn wir oder ein Engel vom Himmel euch ein Evangelium verkünden würde entgegen dem, das wir euch als Evangelium verkündet haben, anathema sei er. Wie wir schon zuvor einmal gesagt haben, so sage ich jetzt wieder: wenn euch jemand ein Evangelium verkündet entgegen dem, das ihr empfangen habt, anathema sei er).

Der vorangehende Text, an den sich die zitierte Stelle anschließt, lässt eindeutig erkennen, dass die christliche Gemeinde der Galater einer äußersten

${ }^{19}$ Vgl. Röm 6, 5-7; Gal 1, 3-4.

${ }^{20}$ ZurBedeutung diesesBegriffsundseinerInterpretationsmöglichkeitensiehe:K.Kuhn,TWNTIV, Stuttgart 1966, 470-475; H. Conzelmann, Der erste Brief an die Korinther, Göttingen ${ }^{12} 1981$, 360-361; Lindemann, Der erste Korintherbrief, S. 388. Im Anschluss an Lindemann entschließe ich mich für die Übersetzung: „Unser Herr, komm!”.

${ }^{21}$ Vgl. Lindemann, Der erste Korintherbrief, S. 388. 
Gefahr ausgesetzt wird. Paulus spricht nämlich von Menschen, die ein anderes Evangelium verbreiten und damit Verwirrung und Unruhe unter den Galatern stiften. Den Inhalt dieses ,neuen” Evangeliums kann man aufgrund der apologetischen Aussagen des Apostels gut rekonstruieren. Die Gegner des Paulus versuchen nämlich, die Galater von der Notwendigkeit des Gesetztes sowie der Beschneidung zu überzeugen, und behaupten, dass man nur über die jüdischen Vorschriften zum wahren Christentum gelangen könne ${ }^{22}$. Eine solche Lehre ist aber keineswegs mit dem zu vereinbaren, was Paulus als Evangelium verkündigt hat. Alle Unruhestifter, die „das Evangelium Christi verdrehen wollen” (Gal 1, 7), trifft der Fluch des Apostels. Den Ernst der Situation unterstreicht noch die Tatsache, dass Paulus weder sich selbst noch einen Engel vom Himmel von seinem ,anathema” ausschließt. Die Reinerhaltung des Evangeliums steht demzufolge an erster Stelle, sodass „bei der Verurteilung der Irrlehrer kein Ansehen der Person gilt"23. Das Faktum, dass sogar ein Engel vom Himmel mit einem Anathem belegt werden kann, scheint auf den ersten Blick, sehr überraschend zu sein, stellt aber die unbedingte Kompromisslosigkeit gegenüber denen heraus, die das Evangelium verändern. Das Anathem trifft demzufolge alle, die eine Lehre verkünden, welche die Heilsbedeutung Christi minimalisiert oder gar völlig unbeachtet lässt. Menschen, die sich für die Verbreitung eines solchen „Evangeliums” einsetzen, gehören nach Paulus nicht Jesus, sondern dem Satan an. Die Gleichsetzung der falschen Verkünder mit dem teuflischen Bereich ist am deutlichsten in 2Kor 11, 3-4 sowie 1314 sichtbar. Der Apostel spricht hier ausdrücklich davon, dass alle, die einen anderen Christus oder ein anderes Evangelium verkünden, mit der alttestamentlichen Schlange, die Eva verführt hat, zu vergleichen sind. Er nennt sie sogar Lügenapostel, unehrliche Arbeiter, die sich als Apostel Christi ausgeben, mit Christus aber nichts zu tun haben. In diesem Vergleich der Irrlehrer mit der Schlange ist bereits ihre Anathematisierung enthalten ${ }^{24}$. Auf den eindeutig diabolischen Ursprung der falschen „Apostolizität” weisen nämlich unmissverständlich die Worte: „... auch der Satan tarnt sich als Engel des Lichts” (2Kor 11, 14) hin. Die falschen Verkünder verhalten sich demzufolge genauso wie der Teufel, der Hauptwidersacher und Feind Gottes, selbst ${ }^{25}$. Denn sie handeln gegen Gott nicht nur deshalb, weil sie eine Irrlehre vertreten, sondern vor allem deshalb, weil sie Anhänger für ihre falschen Ansichten gewinnen wollen. Jede Verkündigung einer Lehre setzt nämlich logischerweise voraus, dass sie sich an bestimmten Personenkreis richtet und darauf zielt, die Zuhörer von der Wahrheit der Lehre zu überzeugen. Darum weißt der Apostel Paulus,

${ }^{22} \mathrm{Vgl}$. Gal 3, 15-22; 5, 1-12.

${ }^{23}$ U. Borse, Der Brief an die Galater, Regensburg 1984, 49.

${ }^{24}$ Vgl. Gen 3, 14: „,weil du das getan hast, bist du verflucht unter allem Vieh und allen Tieren des Feldes".

${ }^{25}$ Vgl. H. Klauck, 2. Korintherbrief, Würzburg ${ }^{3} 1994,83$. 
darum wissen aber auch die „Lügenapostel”. Deshalb versuchen sie, alles dafür einzusetzen, die Menschen vom wahren Glauben an Christus abzubringen. Das Hauptziel einer solchen Aktivität ist die Verführung derjenigen, die unter ihrem Einfluss stehen. Hier liegt der Berührungspunkt zur satanischen Praxis. Denn wie der Teufel Adam und Eva verführt hatte, so tun auch die Irrlehrer, die Paulus mit seinem Anathem belegt. Das Anathem dient demzufolge der eindringlichen Entlarvung der falschen Verkünder sowie der klaren Abgrenzung zwischen dem, was göttlichen, und dem, was teuflischen Ursprungs ist. Es verweist eindeutig darauf, dass die Menschen, die eine Lehre bringen, die im Widerspruch mit dem Evangelium Christi steht, die alle Kräfte für die Verbreitung einer solchen Lehre einsetzen und verführerisch die Gläubigen von Christus abbringen, als Satansapostel bezeichnet werden müssen. Deshalb sind sie verflucht und aus jeglicher Gemeinschaft mit Gott ausgeschlossen.

Der Einsatz des Anathems in Gal 1, 8f bestätigt noch einmal die Bedeutung und den Charakter des Terminus, der aufgrund der Analyse der vorherigen óvó $\theta \varepsilon \mu \alpha$-Stellen definiert wurde. Der Begriff bezieht sich zweifellos auf eine Sphäre, die wegen ihrer Zugehörigkeit zum Satan von Christus völlig getrennt und der Vernichtung durch Gott preisgegeben ist. Die Irrlehrer, die im Galaterbrief anathematisiert werden, gehören nach Paulus eindeutig zu dieser satanischen Sphäre und haben deshalb keinen Anteil an der Gemeinschaft mit Gott. Sogar ein Engel kann dem Anathem unterliegen, wenn er in Wahrheit ein „verkleideter" Diener des Satans ist. Daraus ergibt sich, dass das paulinische $\grave{\alpha} v \alpha ́ \theta \varepsilon \mu \alpha$ all diejenigen trifft, die die systematische Verführung der Menschen und ihre Ablenkung von Christus zum Ziel haben.

e) Zusammenfassung. Die vier Stellen, an denen Paulus óvó $\theta \varepsilon \mu \alpha$ verwendet, ermöglichen, eine eindeutige Definition des Terminus zu formulieren sowie den Personenkreis, gegen den sich das Anathem richtet, zu bestimmen. Das Anathem bedeutet nach paulinischem Verständnis die völlige Scheidung von Christus ${ }^{26}$, die Zugehörigkeit zum Bereich des Satans. Eine solche Begriffsbestimmung ergibt sich aus der Analyse der Perikopen aus Röm 9, 3

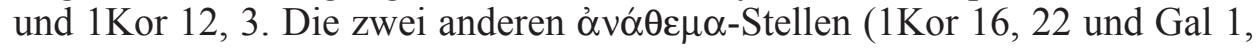
8f) helfen hingegen bei der Präzisierung der Personengruppe, die das Anathem trifft. Aufgrund der genaueren Betrachtung dieser Stellen lässt sich sagen, dass der Einsatz des Anathems bei Paulus zwei wichtige Sachverhalte vorauszusetzen scheint. Anathematisiert werden nämlich diejenigen, die hartnäckig auf Ansichten, Lehren, Verhaltensweisen bestehen, die den christlichen Grundsätzen prinzipiell widersprechen. Die paulinischen Formulierungen: „wenn jemand den Herrn nicht liebt” oder ,wenn jemand ein anderes Evangelium verkündet" weisen eindeutig nicht auf eine sporadische Begebenheit, auf ein einmaliges Vorkommnis, sondern vielmehr auf eine grundsätzliche und bewusste Einstellung hin, die sich gegen Christus den Herrn und sein Evangelium rich-

${ }^{26}$ Vgl. K. Hofmann, Anathema, RACh I, Stuttgart 1950, 429. 
tet. Die Hartnäckigkeit ist demzufolge die erste Voraussetzung, die ein wichtiges Kriterium für den Einsatz des paulinischen Anathems zu sein scheint. Sie genügt Paulus aber nicht, um jemanden zu anathematisieren. Denn die Ausdrücke „den Herrn nicht lieben” (d.h. ihn in Wahrheit hassen) und „ein anderes Evangelium verkünden" setzen ein gewisses aktives Engagement derjenigen voraus, die hier gemeint sind. Die Menschen, die Christus hassen, sowie die falschen Verkünder setzten ex definitione alles dafür ein, um die Gläubigen von dem wahren Jesus abzulenken. Dadurch kämpfen sie gewissermaßen mit Gott und sind als Satansapostel bzw. Antichriste zu bezeichnen. Diese aktive Wirkung zugunsten der Verbreitung des Bösen stellt das zweite Kriterium für den Einsatz des paulinischen Anathems dar. Hartnäckigkeit und aktives Engagement bei der Vernichtung des wahren Glaubens sind demzufolge die wichtigsten Bedingungen, die die von Paulus Anathematisierten zu erfüllen scheinen. In diesem Zusammenhang kann man sich die durchaus berechtigte Frage stellen, wie sich Paulus die eschatologische Zukunft der mit seinem Anathem belegten vorstellt. Sind die vom Apostel Anathematisierten auf ewig verdammt? Dieses Problem scheint Paulus, weniger zu interessieren. Er spricht nicht viel davon, was mit solchen Menschen in der Zukunft passieren wird. Nur an einer Stelle sagt er in Hinblick auf die Irrlehrer, die er früher mit dem Satan verglichen hat, dass ,ihr Ende ihren Taten entsprechen wird” (2Kor 11, 15b). Das Urteil über sie überlässt der Apostel offensichtlich Gott selbst. Eine solche Schlussfolgerung bestätigt Paulus auch im Galaterbrief, wo er über das Ende der anathematisierten Unruhestifter schreibt: „Wer euch verwirrt, der wird das Urteil Gottes zu tragen haben, wer es auch sei" (Gal 5, 10b).

Das paulinische Anathem ist zweifellos eine Maßnahme der Abwehr, die „auf Bewahrung des rechten Glaubens" ${ }^{27}$ zielt. Die in der Literatur gelegentlich vertretene These, es setze die Umkehr und Rettung des Anathematisierten

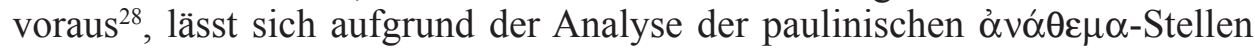
überzeugend nicht beweisen. Der Apostel verliert kein Wort über die eventuelle Bekehrung der mit dem Anathem Belegten. Das scheint, ihn ebenso wenig zu interessieren wie die eschatologische Zukunft der Anathematisierten. Diese Tatsache hängt wahrscheinlich damit zusammen, dass Paulus beim Einsatz seines Anathems davon ausgeht, dass der Anathematisierte kein Interesse an seiner Besserung hat. Der Apostel schließt allerdings die Möglichkeit der Umkehr des Anathematisierten prinzipiell nicht aus, hält aber eine solche Wendung offensichtlich für eher unwahrscheinlich. Paulus hätte nämlich keine Irrlehrer mit seinem Anathem belegen müssen, wenn sie sich vom Irrtum ihrer Thesen hätten abwenden wollen. Man kann also mit einiger Sicherheit sagen, dass das paulinische Anathem mit der Bußpraxis eigentlich kaum

\footnotetext{
${ }^{27}$ Doskocil, Der Bann in der Urkirche, S. 57.

${ }^{28}$ Vgl. ibidem, S. 67.
} 
$\mathrm{zu}$ tun hat ${ }^{29}$. Es vermag dem Anathematisierten keine Buße aufzuerlegen, weil sich der Anathematisierte an seiner Besserung überhaupt nicht interessiert. Das Anathem ist demzufolge in erster Linie der Ausdruck der Sorge des Apostels um die Rechtgläubigkeit der Gemeinden, die er gegründet hat, und nicht der Ausdruck seiner Hoffnung auf die Umkehr und Besserung des Anathematisierten. Das Anathem stellt also eine gewisse Hilfe für diejenigen dar, die unsicher sind, welchem Lehrer, welchem Evangelium und welcher Lebensweise sie folgen sollen. Wer mit einem Anathem belegt ist, der hat sich bereits mit ganzer Kraft und Seele entschieden, dass er hartnäckig gegen Christus, gegen seine Lehre und gegen die christliche Lebensweise kämpfen will. Die Eindeutigkeit einer solchen Entscheidung kann für die anderen auf den ersten Blick manchmal nicht ganz klar sein. Das Anathem schafft deshalb Klarheit und weist deutlich darauf hin, dass der Anathematisierte mit Christus nichts zu tun hat.

In der Literatur wird gelegentlich versucht, das paulinische Anathem mit der sog. Übergabe an den Satan zu identifizieren ${ }^{30}$. Solche Versuche scheinen mir allerdings, nicht ganz überzeugend zu sein. Denn Paulus, der einen Blutschänder von Korinth dem Satan übergibt ${ }^{31}$, spricht eindeutig davon, dass diese strenge Sanktion der Rettung des Sünders dienen soll ${ }^{32}$. Der Apostel bedient sich hier des Ausdrucks ,anathema” nicht, was geradezu Absicht zu sein scheint ${ }^{33}$. Das Anathem wäre nämlich im Fall eines Blutschänders völlig fehl am Platze. Denn wie es oben festgestellt wurde, setzt der Einsatz des Anathems zwei Kriterien voraus: Hartnäckigkeit und aktives Engagement bei der Verbreitung des Bösen. Der erwähnte Blutschänder von Korinth ist zweifellos eines schwer sündhaften Vergehens schuldig. Deshalb wird er dem Satan übergeben, damit sein Fleisch, das ,in Feindschaft gegen Gott lebt”34, vernichtet werden kann. Es wird aber davon nichts gesagt, dass der genannte Sünder andere Menschen für seine gottlose Lebensweise aktiv geworben

${ }^{29}$ Die Auffassung, Anathem sei mit der Bußpraxis verbunden, vertritt Gommenginger, der Anathem als eine Stufe der Exkommunikation versteht, und Doskocil, der Anathem mit der sog. Übergabe an den Satan aus 1 Kor, 5, 5 identifiziert, vgl. A. Gommenginger, Bedeutet die Exkommunikation Verlust der Kirchengliedschaft, ZKTh 73 (1951) 28ff; Doskocil, Der Bann in der Urkirche, S. $63 \mathrm{ff}$.

${ }^{30}$ Vgl. Doskocil, Der Bann in der Urkirche, S. 63ff; G. Schneider, Der Brief an die Galater, Düsseldorf 1964, 31-32, H. Schlier, Der Brief an die Galater, Göttingen ${ }^{15} 1989,41$.

${ }^{31}$ Die Sanktion der Übergabe an den Satan kommt noch einmal in 1 Tim 1, 20 vor. Da aber die Stelle in der neuesten Forschung als ein sekundärer Interpretationsversuch betrachtet wird, lasse ich sie hier außer Acht. Zur Bedeutung der Sanktion siehe: Lindemann, Der erste Korintherbrief, S. $125 \mathrm{ff}$.

${ }^{32}$ Vgl. 1Kor 5, 5: „diesen Menschen dem Satan übergeben zum Verderben seines Fleisches, damit sein Geist am Tag des Herrn gerettet wird".

${ }^{33}$ Die gleiche Auffassung vertritt K. Hofmann (Anathema, S. 429).

${ }^{34}$ So interpretiert A. Lindemann den griechischen Begriff $\sigma \alpha ́ \rho \xi$, siehe Lindemann, Der erste Korintherbrief, S. 127. 
hätte. Die Tatsache, dass Paulus von der Rettung seines Geistes spricht ${ }^{35}$, bezeugt unmissverständlich die feste Überzeugung des Apostels, dass sich der Sünder bekehrt. Die Übergabe an den Satan und das Anathem sind demzufolge keineswegs gleichzusetzen. Das erste stellt eine Zuchtmaßnahme dar, die vor allem auf die Errettung des Betroffenen zielt und die Gemeinde vor der Ansteckungsgefahr schützt. Das andere hingegen ist eine sakrale Formel ${ }^{36}$, die der Gemeinde bei der Abgrenzung des Bösen und des Guten hilft, an der Rettung des Anathematisierten aber wegen seiner Hartnäckigkeit kaum ein Interesse haben kann.

2. Die Johannesbriefe. Der Begriff, ,anathema" taucht in den Johannesbriefen nicht auf. Trotzdem findet man einige Stellen, die in den von Paulus festgelegten Bereich dieses Terminus fallen. Es handelt sich hier vor allem um die Perikopen, die vom Kommen und von der Aktivität des Antichristen sprechen. Im Wort „Antichrist” scheint mir, das Anathem im Sinne des paulinischen Verständnisses bereits enthalten zu sein. Denn der Begriff „Antichrist” bezeichnet, seiner wörtlichen Bedeutung nach, eine Person, die antichristliche Lehre und Verhaltensweise hartnäckig verkündet. Dieser Terminus scheint demzufolge, mit dem Inhalt des paulinischen Anathems zu korrespondieren. Um diese Ansicht aufgrund der exegetischen Analyse zu bestätigen, muss man allerdings die folgenden Antichrist-Stellen unter die Lupe nehmen: 1Joh 2, 1819 und 22-23; 1Joh 4, 3; 2Joh 7.

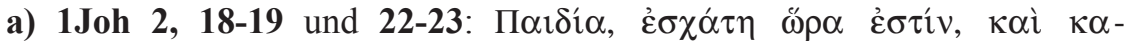

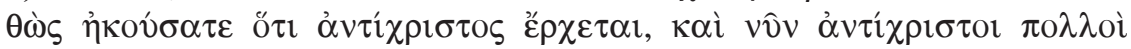

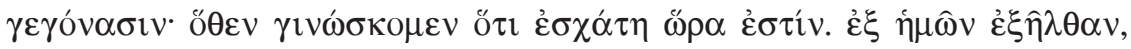

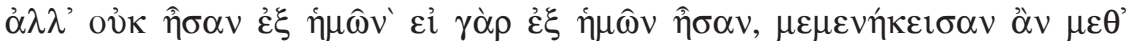

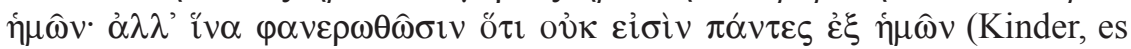
ist die letzte Stunde. Ihr habt auch schon gehört, dass der Antichrist kommt und dass jetzt viele Antichriste aufgetaucht sind. So erkennen wir, dass es die letzte Stunde ist. ${ }^{19}$ Sie kamen aus unserer Mitte, aber sie waren nicht von uns: denn wenn sie von uns gewesen wären, wären sie mit uns geblieben; dies geschah, damit es offenbar werde, dass sie alle nicht von uns sind).

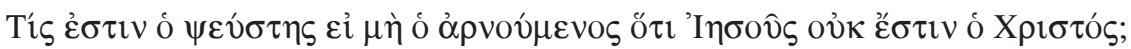

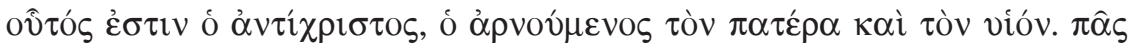

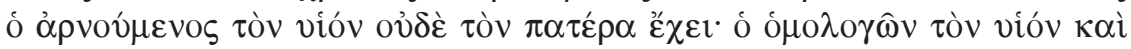

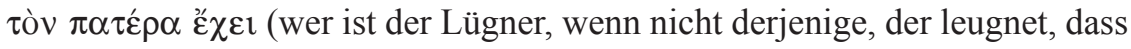
Jesus der Christus ist? Dieser ist der Antichrist, derjenige, der den Vater und

${ }^{35}$ Eine interessante wissenschaftliche Diskussion über die endzeitliche Rettung des Blutschänders von Korinth präsentiert A. Lindemann (Der erste Korintherbrief, S. 127ff).

${ }^{36}$ Vgl. Hofmann, Anathema, S. 429. 
den Sohn leugnet. Jeder, der den Sohn leugnet, hat auch den Vater nicht: wer den Sohn bekennt, der hat auch den Vater).

Die zwei gerade zitierten Stellen gehören zu einem längeren $\mathrm{Abschnitt}^{37}$, in dem der Verfasser des Briefes die Mitglieder einer christlichen Gemeinde vor falschen Verkündern warnt. Er versucht, seine Adressaten davon zu überzeugen, dass sie aufgrund der Salbung Christi den richtigen Glauben empfangen haben $^{38}$. Diese Salbung versichert die Gemeinde, dass sie die Wahrheit kennt. Deshalb werden alle, die eine andere Salbung verkünden als die, welche von Jesus Christus kommt, Antichriste genannt. Sie bringen Lüge und haben keine Wahrheit. Christus und Antichrist, Wahrheit und Lüge stellen zwei wichtige Antithesen dar, die sich wie ein roter Faden durch die ganze Perikope hindurch ziehen. Das Faktum, dass der Antichrist dem Christus Jesus gegenübergestellt wird, ist theologisch hoch bedeutsam. Es verweist nämlich darauf, dass der Antichrist als ein Gegenspieler Jesu, als ein Feind dessen zu verstehen ist. Diese Tatsache verdeutlicht noch die Vorsilbe „Anti-”, die „das gegen Christus Gerichtete oder den Versuch, sich an die Stelle Christi zu setzen" ${ }^{39}$, ausdrückt. Der Antichrist leugnet demzufolge mit seiner ganzen Existenz die wirkliche Heilsbedeutung Jesu Christi. Die Formulierung: ,der ist der Antichrist, der leugnet, dass Jesus der Christus ist" präzisiert deutlich den Charakter des Antichristen. Der Antichrist erkennt nämlich Jesus als den Erlöser und Heiland nicht an und verkündet entweder sich selbst oder jemanden anderen als den

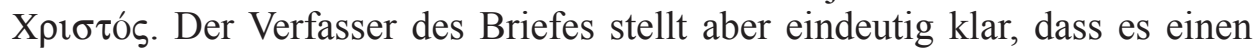
Christus außer Jesus überhaupt nicht gibt: „...und das Blut seines Sohnes Jesus reinigt uns von aller Sünde" (1 Joh 1, 7b). Jeder, der etwas anderes bringt, verkündet demzufolge eine falsche Lehre. Er gehört weder Christus noch Gott dem Vater an. Denn ,der Unglaube gegen Jesus richtet sich letztlich gegen den Vater" ${ }^{40}$. Der Antichrist ist deshalb als Lügner zu bezeichnen ${ }^{41}$, weil er nicht die Wahrheit in Jesus Christus verkündet. Die Tatsache, dass sich der Verfasser des Briefes so scharf gegen den Antichristen äußert, bezeugt, dass sich die Gemeinde in einer tödlichen Bedrohung befindet. Jemand versucht, sie vom Glauben an Jesus abzulenken. Die Gefahr wird noch dadurch vergrößert, dass diese Verführer formal der Gemeinde angehört haben. Aus diesem Grunde ist die Bezeichnung „Antichrist”, die hier im Bezug auf die falschen Verkünder gebraucht wird, völlig verständlich. Es handelt sich nämlich um klare und eindeutige Abgrenzung zwischen dem, was Wahrheit, und dem, was Lüge ist. Der Verfasser des Briefes musste sich einer solchen Begrifflichkeit bedienen,

${ }^{37}$ Eine inhaltliche Einheit, zu der die von mir vorgestellten Zitate gehören, bildet die Perikope 1Joh 2, 18-27.

${ }^{38} \mathrm{Vgl}$. 1Joh 2, 20.

${ }^{39}$ J. Beutler, Die Johannesbriefe, Regensburg 2000, 72.

${ }^{40}$ Ibidem, S. 74.

${ }^{41}$ Vgl. 1Joh 2, 22. 
die seine Adressaten sofort als Warnung erkennen konnten. Wenn er sich im Kampf gegen die Irrlehrer für den Terminus „Antichrist” entscheidet, bedeutet dies, dass diese Bezeichnung äußerst negative Assoziationen hervorrufen musste. In diesem Begriff steckt offenbar mehr als nur eine bloße Ablehnung der falschen Verkünder. Denn das Wort „Antichrist” ordnet alle, die eine Irrlehre bringen, in eine Sphäre ein, die prinzipiell gegen Jesus Christus und damit gegen Gott ausgerichtet ist. Man kann demzufolge mit Sicherheit sagen, dass diese Sphäre, die nicht nur mit Gott nichts zu tun hat, sondern auch mit ihm systematisch kämpft, nach christlichem Verständnis zum Satan gehören muss $^{42}$. Der Antichrist ist deshalb als Bote des Satans zu interpretieren und stellt aus diesem Grunde eine große Gefahr für die Gläubigen dar.

Die semantische Analyse des Terminus „Antichrist” sowie die Aussagen des Verfassers des Briefes, die den Sinn dieses Terminus näher charakterisieren lassen, machen deutlich, dass die Gruppe der Personen, die als Antichriste bezeichnet werden, mit denen übereinstimmt, die von Paulus mit dem Anathem belegt werden. Denn die Antichriste verbreiten, genauso wie die Anathematisierten, hartnäckig und programmatisch eine Lehre bzw. eine Verhaltensweise, die gegen Christus und sein Evangelium gerichtet ist. Die beiden Gruppen sind also aktiv engagiert bei der Bekämpfung des wahren christlichen Glaubens. Sie werden außerdem gleichermaßen mit dem Satan und seiner Praxis in Verbindung gebracht. Die Begriffe ,anathema” und „Antichrist” dienen eindeutig der Festlegung einer Grenzlinie zwischen Wahrheit und Lüge. Aus diesen Gründen kann man mit einiger Sicherheit sagen, dass die von Paulus Anathematisierten und die im ersten Johannesbrief als Antichriste Bezeichneten eine und dieselbe Menschengruppe darstellen.

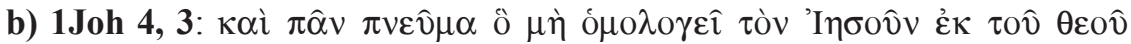

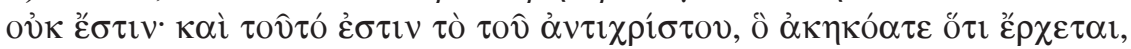

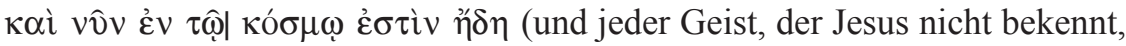
ist nicht aus Gott: das ist der Geist des Antichristen, über den ihr gehört habt, dass er kommt und schon jetzt in der Welt ist).

Die Stelle bringt den Begriff „Antichrist” wiederum mit den Irrlehrern in Verbindung. Diejenigen, die Jesus nicht bekennen ${ }^{43}$, kommen nicht von Gott, sondern vom Antichristen. Interessant an dieser Stelle ist allerdings die Tatsache, dass sich der Verfasser des Ausdrucks $\pi v \varepsilon \hat{v} \mu \alpha$ (Geist) in Hinblick auf

${ }^{42}$ Diese Auffassung bestätigt die Aussage des Verfassers des Briefes, der schreibt: ,... dass das Wort Gottes in euch bleibt und dass ihr den Bösen besiegt habt" (1Joh 2, 14b). Das Bleiben im Wort Gottes widerspricht also dem Bösen, der hier wohl mit dem Satan zu identifizieren ist. Will man diese Feststellung negativ formulieren, so ergibt sich, dass derjenige, in dem das Wort Gottes nicht bleibt, unter dem satanischen Einfluss steht.

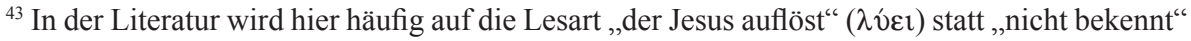

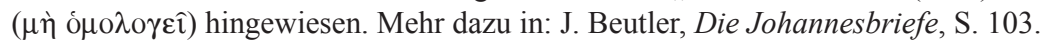


die falschen sowie wahren ${ }^{44}$ Verkünder bedient. Mit dieser Formulierung verweist er eindeutig auf den geistigen Ursprung einer Lehre, auf die Inspiration, aus welcher sie ,geboren ist”. Jede Verkündigung geht demzufolge auf einen Geist zurück. Die Gemeinde soll deshalb ein klares Kriterium in die Hand bekommen, nach welchem sie den Geist Gottes vom Geist des Antichristen unterscheiden könnte. Ein solches Kriterium ist das Bekenntnis zu Jesus und seiner Heilsbedeutung. Die vom Verfasser des Briefes bewusst konstruierte Entgegensetzung vom Geist Gottes und Geist des Antichristen macht deutlich, dass der Antichrist eine gegnerische Macht, eine feindliche Größe gegenüber Gott darstellt. Auf der Ebene der Geister kann man hier wohl an den Satan denken, der im Neuen Testament immer als der größte Gegner Gottes erscheint $^{45}$. Das Faktum, dass der Verfasser des ersten Johannesbriefes die falschen Verkünder mit dem Geist des Antichristen in Verbindung bringt, enthält bereits nicht nur ihre Diskreditierung, sondern auch eine eindeutige Verfluchung. Denn die Formulierungen „er ist aus Gott nicht” und „das ist der Geist des Antichristen" setzten logischerweise voraus, dass sich derjenige, der sich unter dem Einfluss eines solchen Geistes befindet, von Gott getrennt hat und dadurch im Dienst des Bösen steht. Die ganze Sphäre des Satans wird allerdings im Johannesbrief von vornherein zur Vernichtung durch den Sohn Gottes verurteilt ${ }^{46}$. Die Bestimmung zur Destruktion durch Gott weist hingegen auf die vorangegangene Verfluchung dessen hin, den Gott vernichten wird ${ }^{47}$. Daraus ergibt sich, dass auch diejenigen, die aus dem Geist des Antichristen schöpfen als verflucht zu betrachten sind. Denn sie sind nicht aus Gott, sondern gehören zum Bereich des Satans, den Christus besiegt hat. Aus diesem Grundes wäre es wohl keine Übertreibung, zu behaupten, dass der Begriff „Antichrist” eine Formel darstellt, die die Verfluchung, d.h. vollständige Trennung von Christus, des Betroffenen voraussetzt.

Die Analyse der Perikope stellt klar, dass der Verfasser des ersten Johannesbriefes den Begriff ,Antichrist” eindeutig auf die falschen Verkünder bezieht. Er macht zugleich deutlich, dass dieser Terminus eine aktive antigöttliche Kraft bezeichnet, die wohl mit dem Teufel in Verbindung steht. Eine solche Begriffsbestimmung entspricht völlig dem Bereich, in den das paulinische Anathem fällt, und lässt feststellen, dass sich der Antichrist vom Anathematisierten inhaltlich nicht unterscheidet.

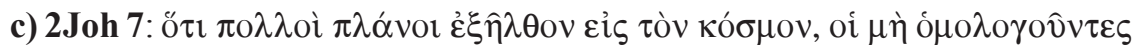

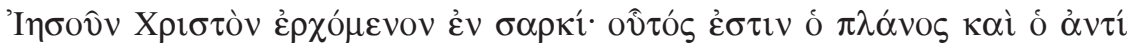
$\chi \rho ı \sigma \tau \varsigma \varsigma$ (viele Verführer sind in die Welt hinausgegangen, die nicht beken-

${ }^{44}$ Vgl. 1Joh 4, 2.

${ }^{45}$ Vgl. Mt 4, 1-11; Mk 1, 13; Lk 4, 1-13; Offb 20, 10.

${ }^{46} \mathrm{Vgl} \mathrm{1Joh} \mathrm{3,} \mathrm{8:} \mathrm{„Der} \mathrm{Sohn} \mathrm{Gottes} \mathrm{aber} \mathrm{ist} \mathrm{erschienen,} \mathrm{um} \mathrm{die} \mathrm{Werke} \mathrm{des} \mathrm{Teufels} \mathrm{zu}$ zerstören".

${ }^{47} \mathrm{Vgl}$. Behm, ỏvó $\theta \varepsilon \mu \alpha$, TWNT I 356. 
nen, dass Jesus Christus im Fleisch gekommen ist: das ist der Verführer und der Antichrist).

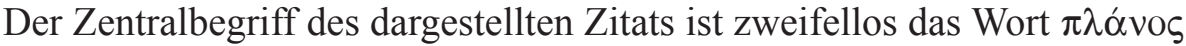
(Verführer). Er kommt in diesem kurzen Abschnitt zwei Mal vor und bezeichnet, seiner semantischen Bedeutung zufolge, einen Menschen, die andere in die Irre führt. In diesem Zusammenhang ist allerdings zu beachten, dass die Termini ,verführen” oder ,,Verführer” immer zum Wortfeld der Gegenspieler

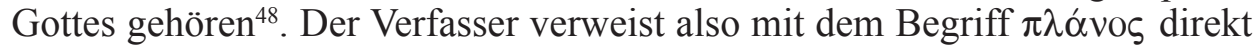
zu Anfang der Perikope darauf, dass er im Weiteren eine Aussage über die Feinde Gottes machen wird. Zunächst stellt er fest, dass die Verführer schon in die Welt ausgezogen sind. Diese Anmerkung ähnelt in jeder Hinsicht dem, was in 1Joh 4, 1 gesagt wird: ,viele falschen Propheten sind in die Welt hinausgezogen". Der Verführer kann demzufolge mit einem Pseudopropheten identifiziert werden. Der Aspekt einer falschen Verkündigung wird dadurch deutlich hervorgehoben. Dass es sich an der zitierten Stelle tatsächlich um eine Irrlehre handelt, bestätigt der Verfasser selbst, indem er klarstellt, dass die genannten Verführer das Kommen Jesu Christi im Fleisch leugnen. Ähnlich wie in 1Joh wird auch hier die Verbreitung einer falschen Christologie problematisiert. Deshalb sollen die Adressaten des Briefes darüber im Klaren sein, dass alle Falschlehrer als Verführer, d.h. Gegner Gottes, zu betrachten sind. Die Bezeichnung „Antichrist”, die zum Schluss des Abschnitts auftaucht, unterstreicht noch die Zugehörigkeit der Verführer zum antigöttlichen und antichri-

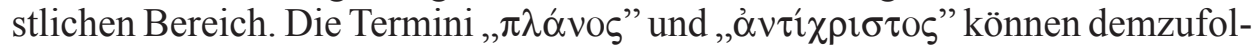
ge inhaltlich gleichgesetzt und als Synonyme verstanden werden. Eine solche Gleichsetzung bestätigt noch einmal, dass der Begriff, „Antichrist” eine Person betrifft, die zum einen sich hartnäckig für die Verbreitung des Bösen und für die Gewinnung der Anhänger einsetzt, zum anderen aus der Gemeinschaft mit Gott ausgegrenzt ist. Sehr interessant scheint in diesem Zusammenhang die Tatsache zu sein, dass der Verfasser des Briefes konkrete Anweisungen gibt, wie man sich gegenüber den Antichristen, d.h. Verführern, zu verhalten habe. Er sagt nämlich ausdrücklich davon, dass man solche Pseudopropheten weder ins Haus aufnehmen noch grüßen solle. Sonst mache man sich mitschuldig an ihren bösen Taten ${ }^{49}$. Die Verweigerung des Grußes, die der Verfasser als einen eindringlichen Rat formuliert, erscheint mir in Hinblick auf das Verständnis der Bedeutung des Begriffs „Antichrist” sehr wichtig. Der Gruß war nämlich im Orient mehr als eine bloße Höfflichkeitsbezeugung, er war zugleich Segenswunsch ${ }^{50}$. Dieser Interpretation zufolge kann man vermuten, dass die Tatsache, dass man den Antichristen den Gruß, d.h. den Segenswunsch, verweigert, ihren Grund in der Überzeugung hat, dass der Antichrist als verflucht

\footnotetext{
${ }^{48}$ Vgl. Beutler, Die Johannesbriefe, S. 158.

${ }^{49} \mathrm{Vgl}$. 2Joh, 10-11.

${ }^{50}$ Vgl. L. Brun, Segen und Fluch im Urchristentum, Oslo 1931, 29.
} 
gelten soll. Segen und Fluch stellen nämlich einen äußersten Widerspruch dar, genauso wie Christus und der Antichrist in einem streng antithetischen Verhältnis zueinander stehen. Der Verfluchte darf nicht gesegnet werden, so wie der Antichrist zum Christus nicht gemacht werden darf. Segnet aber jemand den Verfluchten, so schließt er sich ihm damit an, akzeptiert seine Verhaltensweise und wird selbst verflucht. Diese Deutung stellt klar, warum der Christ dem Antichristen den Gruß (Segen) verweigern soll. Denn den Segen auf den Antichristen zu beziehen, würde in sich ein Widerspruch sein, weil der Antichrist unter dem Fluch seiner antigöttlichen Aktivität steht und deshalb keinen Segen verdient.

Zusammenfassend lässt sich sagen, dass der Antichrist und der von Paulus Anathematisierte gleichermaßen mit dem Fluch belegt sind. Man darf ihn nicht segnen, weil er gegen Christus kämpft. Aus diesem Grunde muss er auch als Feind Gottes identifiziert werden. Er stellt für die Gemeinde eine große Gefahr dar und ist deshalb radikal abzulehnen.

d) Zusammenfassung. Der von mir untersuchte Terminus „Antichrist” scheint, viele Gemeinsamkeiten mit dem Wortfeld des paulinischen Anathems aufzuweisen. Zum Ersten werden die beiden Begriffe im Bezug auf einen Bereich verwendet, der prinzipiell gegen Gott und Christus eingestellt ist. Die Verknüpfung dieses Bereiches mit dem Satan ist in den Johannesbriefen sowie bei Paulus auf verschiedene Weise zum Ausdruck gebracht. Zum Zweiten dienen die beiden Termini der klaren Abgrenzung zwischen Wahrheit und Lüge sowie helfen der christlichen Gemeinde, den richtigen Weg des Glaubens $\mathrm{zu}$ gehen. Zum Dritten werden die beiden Bezeichnungen nur auf diejenigen bezogen, die hartnäckig in einem Irrtum bleiben und sich aktiv für die Verbreitung des Irrtums einsetzen, um möglichst viele Anhänger ihrer falschen Lehren zu gewinnen. Zum Vierten werden die Anathematisierten sowie die Antichriste als verflucht betrachtet. Es wird sowohl bei Paulus als auch in den Johannesbriefen nichts Genaues über die eschatologische Zukunft der beiden Gruppen berichtet. Die Möglichkeit ihrer Umkehr ist zwar an keiner Stelle eindeutig ausgeschlossen; die Hoffnung auf ihre Bekehrung wird aber weder bei Paulus noch in den Johannesbriefen problematisiert. Dies lässt den Schluss ziehen, dass der Einsatz der Begriffe ,anathema” und „Antichrist” tiefgehende, satanische Hartnäckigkeit der Betroffenen voraussetzt.

Aus den dargestellten Gründen lässt sich als Endergebnis sagen, dass das paulinische Anathem sowie der in den Johannesbriefen verwendete Terminus „Antichrist” auf eine gemeinsame Basis zurückgehen und an dieselben theologischen Vorstellungen knüpfen.

3. Der Hebräer- und der zweite Petrusbrief. Der paulinische Ausdruck óvó $\theta \varepsilon \mu \alpha$ sowie der in den Johannesbriefen auftauchende Terminus „Antichrist" sind nicht die einzigen Begriffe, an die der Vorstellungsbereich 
des Fluches im Neuen Testament gebunden wird. Es kommt nämlich in den

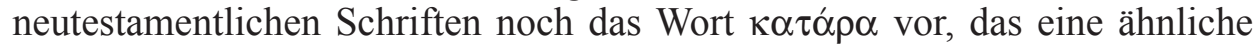
semantische Bedeutung wie ỏvó $\theta \varepsilon \mu \alpha$ hat. Es bezeichnet ebenso die Sphäre des Verfluchten, der Vernichtung durch Gott Preisgegebenen ${ }^{51}$. Paulus selbst bedient sich dieses Begriffs, wenn er vom Fluch des Gesetzes spricht ${ }^{52}$. Auch im Jakobusbrief wird $\kappa \alpha \tau \alpha ́ \rho \alpha$ einmal zur Verdeutlichung der Macht der Zunge gebraucht ${ }^{53}$. Im Bezug auf konkrete Personen wird der Terminus allerdings nur im Hebräerbrief sowie im zweiten Petrusbrief verwendet. Die entsprechenden

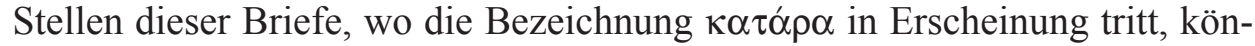
nen sich deshalb als Beitrag zum Thema des Anathems erweisen. In diesem Zusammenhang kommen die folgenden Perikopen in Betracht: Hebr 6, 4-8 und 2Petr 2, 14.

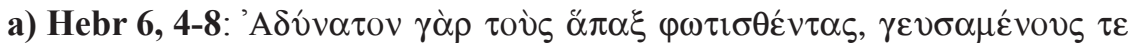

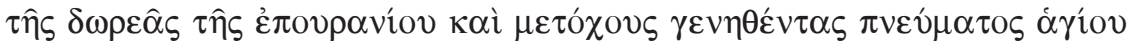

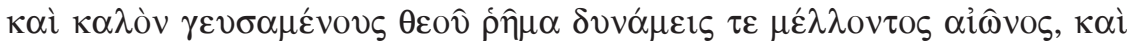

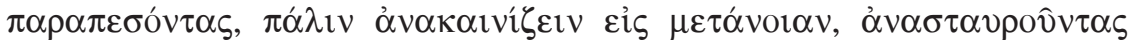

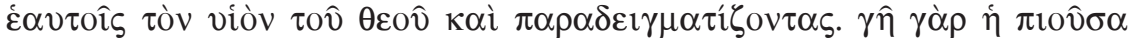

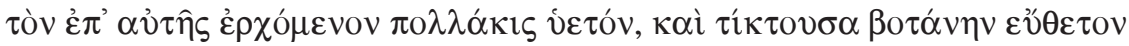

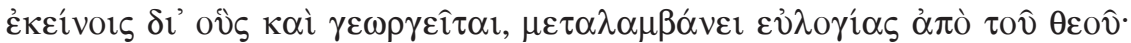

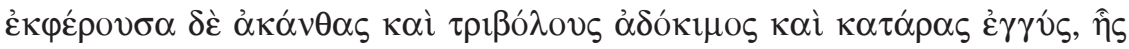

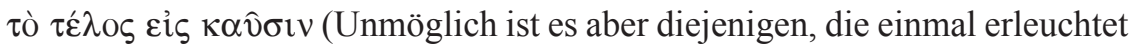
wurden, und nicht nur von der himmlischen Gabe gegessen haben, sondern auch des Heiligen Geistes teilhaftig geworden sind, und rechtes Wort Gottes gekostet haben und die Kräfte der zukünftigen Zeit, und die dennoch abgefallen sind, wiederum zur Umkehr zu erneuern, sie kreuzigen den Sohn Gottes für sich selbst und stellen ihn zur Schau. Denn ein Boden, der den Regen aufnimmt, der häufig auf ihn niedergeht, ein Boden, der nützliches Gewächs hervorbringt für die, die ihn bestellen, empfängt den Segen von Gott her. Wenn er aber Dornenpflanzen und Disteln hervorbringt, wenn er unbrauchbar und dem Fluche nahe ist, dessen Enden führt zum Verbrennen).

Bei der Analyse dieser Perikope steht in erster Linie das theologische Problem zur Entscheidung, was der Verfasser hier als unmöglich betrachtet. Die Stelle spricht nämlich eindeutig davon, dass es unmöglich ist, die einmal Erleuchteten wiederum zur Umkehr zu erneuern. Gerd Schunack hat sehr überzeugend dargelegt, dass es sich hier nicht um eine disziplinarische, kirchenrechtliche Frage handelt, wie man mit den sog. „lapsi” umzugehen hat ${ }^{54}$. Denn die Formulierungen ,erleuchtet worden sein” und „abgefallen sein”, die

\footnotetext{
${ }^{51}$ Vgl. Doskocil, Der Bann in der Urkirche, S. 58.

${ }^{52} \mathrm{Vgl}$. Gal 3, 10 und 13.

${ }^{53}$ Vgl. Jak 3, 10.

${ }^{54}$ Vgl. G. Schunack, Der Hebräerbrief, Zürich 2002, 80.
} 
hier eine deutliche Antithese bilden, bezeichnen nach Schunack eine grundsätzliche Existenzbestimmung; sie beziehen sich demzufolge nicht auf einen lebensgeschichtlich einmaligen $\mathrm{Akt}^{55}$. Erleuchtet sind diejenigen, die die Gabe des Heiligen Geistes und die Wirkungen der kommenden Heilszeit bereits gekostet und erfahren haben. Diese existenzielle Erfahrung des Heils in Jesus Christus steht im äußersten Widerspruch mit dem Abfall von dem, was man zuvor als heilsbringende Gabe ,geschmeckt" hat. Derjenige, der abgefallen ist, hat keineswegs nur eine schwere Sünde begangen, sondern sich von Gott und seiner Gnade willentlich und definitiv abgewandt. Es geht also nicht nur um ein sündhaftes Vergehen des Abgefallenen, sondern um eine grundsätzliche Entscheidung gegen Gott, die durch das Faktum der vorherigen Erkenntnis der göttlichen Gnade noch stärker unterstrichen wird. Eine solche Entscheidung gegen den Urheber des Heils drückt sich konkret in Form der Kreuzigung des Sohnes Gottes aus. Der Terminus „Kreuz” bzw. „kreuzigen” bedeutet im Hebräerbrief den definitiven Widerspruch gegen Jesus ${ }^{56}$ und verweist auf eine prinzipielle Einstellung der Kreuzigenden, welche die totale Vernichtung Christi zum Ziel hat. Wichtig ist dabei auch der öffentliche Charakter dieser Vernichtung, welchen der Verfasser des Briefes der Kreuzigung des Sohnes Gottes durch den Abgefallenen beimisst. Der Begriff $\pi \alpha \rho \alpha \delta \varepsilon \imath \gamma \mu \alpha \tau i \zeta \omega$ (zur Schau stellen, zum Gespött machen, öffentlicher Schande preisgeben), der an der behandelten Stelle in seiner partizipialen Form $\pi \alpha \rho \alpha \delta \varepsilon 1 \gamma \mu \alpha \tau i \zeta o v \tau \alpha \varsigma$ gebraucht wird, bezeichnet zweifellos eine Handlung, die nach außen gerichtet ist, die bei anderen ein bestimmtes Interesse erwecken soll. Der Abfall von Gott konkretisiert sich demzufolge nicht nur in der innerlichen Absage an Jesus, sondern auch in einer äußeren Aktivität, die darauf zielt, andere Menschen gegen Gott in Bewegung zu setzen. Aus diesem Grunde ist es unmöglich, dass die so verstandenen Abgefallenen zur Umkehr erneuert werden könnten. Denn man kann nicht „Gott gegen Gott in Anspruch nehmen, bei endgültig vollzogenem Widerspruch gegen das Ereignis der Gnade Gottes erneut das Ereignis der Gnade Gottes in Anspruch nehmen"57. Die Tatsache, dass die Umkehr nicht mehr möglich ist, setzt also die Entscheidung des Abgefallenen voraus, die überhaupt keinen Raum für seine eventuelle Bekehrung lässt. Den Abfall im Sinne des Verfassers des Hebräerbriefes kann man demzufolge als einen Zustand definieren, der sowohl von unglaublicher Hartnäckigkeit als auch groBer Bereitschaft des Betroffenen zur aktiven Vernichtung Gottes ausgeht.

Das in V. $7 \mathrm{f}$ vom Verfasser des Briefes dargestellte Gleichnis führt deutlich

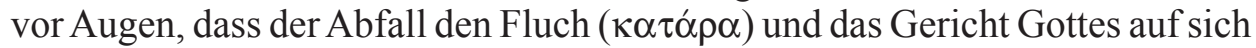
zieht. Der Abgefallene gilt demzufolge als verflucht und wird der Vernichtung durch Gott preisgegeben. Den Begriff $\kappa \alpha \tau \alpha$ $\rho \alpha$ bezieht der Verfasser also ein-

\footnotetext{
${ }^{55}$ Vgl. ibidem, S. 81.

${ }^{56}$ Vgl. ibidem.

${ }^{57}$ Ibidem.
} 
deutig auf eine Personengruppe, die sich zum einen hartnäckig und endgültig gegen Gott entschieden hat und zum anderen dafür einsetzt, den Unglauben gegen Jesus zu verbreiten. Damit scheint es mir ausreichend nachgewiesen zu sein, dass dieser Terminus inhaltlich dem paulinischen Anathem entspricht.

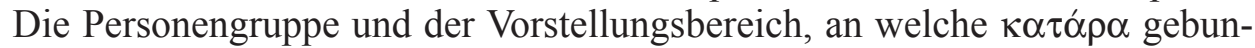
den ist, korrespondiert völlig mit dem Wortfeld, welches das Anathem bei Paulus betrifft. Deshalb kann man sagen, dass die Termini óo $v \alpha \theta \varepsilon \mu \alpha$ sowie $\kappa \alpha \tau \alpha ́ \rho \alpha$ durchaus als Synonyme verstanden werden können.

b) 2Petr 2, 14: ỏ $\theta \alpha \lambda \mu$ ò̀

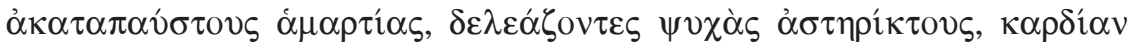

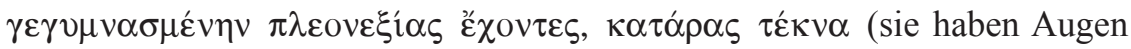
voll Gier nach der Ehebrecherin und sind unersättlich in der Sünde, sie locken haltlose Seelen an. Sie haben in der Habgier geübte Herzen, Kinder des Fluches).

Auf diese Art und Weise charakterisiert der Verfasser des zweiten Petrusbriefes Menschen, die er als $\psi \varepsilon v \delta о \pi \rho \circ \varphi \hat{\eta} \tau \alpha \iota$ nennt. Es handelt sich ohne Zweifel um Falschverkünder, die ,verderbliche Irrlehren verbreiten und den Herrscher, der sie freigekauft hat, verleugnen" (2Petr 2, 1). Der inspirierte Autor ist in der Wahl der Bezeichnungen, mit Hilfe deren er die Irrlehrer beschreibt, nicht heikel. Er nennt sie frech, anmaßend, Quellen ohne Wasser, Sklaven des Verderbens, Hunde und Säue ${ }^{58}$. Die Schärfe einer solchen Ausdrucksweise bezeugt, dass die Pseudopropheten eine ernst zu nehmende Bedrohung für die christliche Gemeinde darstellen. Sie werden vom Verfasser als Nachfolger Bileams bezeichnet, der in der jüdischen Überlieferung als Vater der Verführung gilt ${ }^{59}$. Die Tatsache, dass sie dem Christentum angehört und ,den Herrn und Retter Jesus Christus erkannt hatten” (2Petr 2, 20), verschlimmert noch ihre Situation. Denn „es wäre besser für sie, den Weg der Gerechtigkeit gar nicht erkannt zu haben, als ihn erkannt zu haben und sich danach von dem heiligen Gebot abzuwenden" (2Petr 2, 21). Auf eine ähnliche Formulierung ist man bereits bei der Behandlung des Hebräerbriefes gestoßen, wo vom Abfall der Erleuchteten die Rede war. Die Ausdrücke ,den Weg der Gerechtigkeit erkannt haben” und „erleuchtet worden sein” sind wohl gleichzusetzen und verweisen auf eine grundsätzliche Existenzbestimmung, die das Christsein charakterisiert. Dieser Interpretation zufolge hat derjenige, der den Weg der Gerechtigkeit erkannt hat, sowie derjenige, der erleuchtet worden ist, die Heilswirklichkeit Gottes und seine Gnade erfahren und nach menschlichen Möglichkeiten auch begriffen. Die Formulierung ,sich von dem heiligen Gebot abwenden" bedeutet hingegen eine Existenzbestimmung, die das Gegenteil des Christseins zum Ausdruck bringt. Derjenige, der sich von dem

\footnotetext{
${ }^{58}$ Vgl. 2Petr 2, 10b; 17; 19a; 22.

${ }^{59}$ Vgl. O. Knoch, Der Erste und Zweite Petrusbrief. Der Judasbrief, Regensburg 1990, 268.
} 
heiligen Gebot abgewandt hat, hat bewusst und definitiv eine antichristliche Stellung genommen. Das volle Bewusstsein bei einer solchen Entscheidung gegen Gott hebt ausdrücklich deren Hartnäckigkeit hervor. „Der vom Gebot Abgewandte" will nicht nur Christus nicht mehr angehören, sondern vor allem ihn und seine Lehre bekämpfen. Darauf deutet die Formulierung ,sie werden verderbliche Irrlehren verbreiten und den Herrscher, der sie freigekauft hat, verleugnen" hin. Über die so charakterisierten Irrlehrer spricht der Verfasser des Briefes ein klares Urteil aus: „das Gericht über sie bereitet sich seit langem vor, und das Verderben, das ihnen droht, schläft nicht" (2Petr 2, 3b). Er vergleicht das Ende der Falschverkünder mit der Verurteilung des Satans und der Engel, die sich entschieden, gegen Gott zu kämpfen ${ }^{60}$. Damit deutet er an, dass sich die Irrlehrer genauso wie die abgefallenen Engel verhalten und deshalb das Gericht Gottes verdienen. Der Verfasser bedient sich in diesem

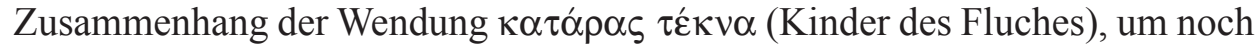
stärker die Zugehörigkeit der Pseudopropheten zum abgefallenen Bereich des Satans zu betonen. Die Irrlehrer sollen als verflucht gelten, weil sie eine Doktrin und Verhaltensweise bringen, die auf die Ablenkung der haltlosen Menschen vom Glauben an Jesus Christus zielt. Sie sind deshalb als Gegner Gottes zu bezeichnen, greifen Gott an und versuchen, ,viele Anhänger zu finden” (2Petr 2,2). Ihre feindliche Einstellung gegenüber Jesus und seiner Sache sowie ihre Hartnäckigkeit sind der Grund dafür, dass sie mit dem Fluch belegt werden. „Kinder des Fluches” stellt also eine Formel dar, die darauf hinweist, dass die mit diesem Ausdruck Bezeichneten aus jeglicher Gemeinschaft mit Gott ausgegrenzt sind.

DaszweifacheKriterium,,derHartnäckigkeit”und,,desaktivenEngagements bei der Verbreitung einer antichristlichen Lehre bzw. Verhaltensweise" trifft im Fall der Pseudopropheten aus dem zweiten Petrusbrief völlig zu. Die Falschverkünder werden deutlich mit dem teuflischen Bereich in Verbindung

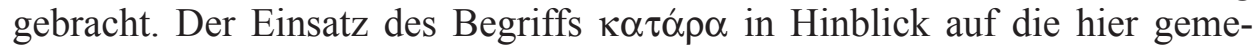
inten Irrlehrer entspricht demzufolge dem, wie der Terminus $\alpha$ vó $\theta \varepsilon \mu \alpha$ bei Paulus gebraucht wird. Aus diesem Grunde lässt sich sagen, dass die beiden Bezeichnungen gleichbedeutend sind.

d) Zusammenfassung. Die Analyse der entsprechenden Stellen aus dem Hebräer- und dem zweiten Petrusbrief hat nachgewiesen, dass sich die Termini

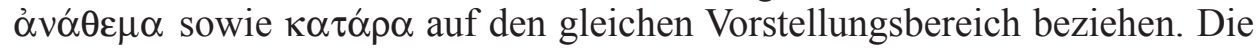
beiden Begriffe weisen auf eine prinzipiell gegen Gott und Christus gerichtete Einstellung des Betroffenen hin, dienen der klaren Abgrenzung zwischen Wahrheit und Lüge, und werden präzis gemäß dem zweifachen Kriterium „,der Hartnäckigkeit” und „des aktiven Engagements bei der Verbreitung des

${ }^{60}$ Vgl. 2Petr 2, 4: ,Gott hat auch die Engel, die gesündigt haben, nicht verschont, sondern in die finsteren Höhlen der Unterwelt verstoßen”. 
Bösen” eingesetzt. Aus diesen Gründen kann man als Endergebnis feststellen,

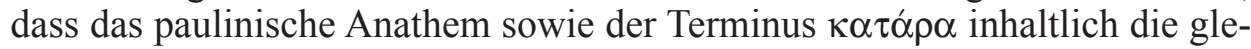
iche Bedeutung und Anwendung haben.

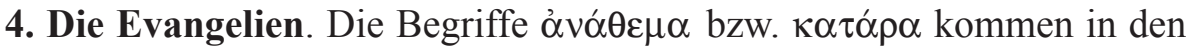
Evangelien in ihrer substantivischen Form nicht vor ${ }^{61}$. Es werden allerdings an wenigen Stellen die Verben $\alpha{ }^{\prime} \nu \alpha \theta \varepsilon \mu \alpha \tau i \zeta \omega$ sowie $\kappa \alpha \tau \alpha \rho \alpha ́ \alpha \mu \alpha \imath$ gebraucht, die traditionell mit „verfluchen”, „verwünschen” übersetzt werden. Es soll jetzt listenartig aufgezeigt werden, wo und in welchem Kontext diese Termini in Erscheinung treten.

Über Petrus, der am Hof des Hohenpriesters zum dritten Mal als Jünger Jesu erkannt wird, berichtet Mk 14, 71:,Er aber begann zu fluchen (ó $\delta \dot{\varepsilon} \eta \eta p \xi \alpha \tau o$ $\left.\dot{\alpha} v \alpha \theta \varepsilon \mu \alpha \tau^{\prime} \zeta \zeta \varepsilon \imath v\right)$ und zu schwören: Ich kenne diesen Menschen nicht". Vom Feigenbaum, zu dem Jesus gesagt hatte, dass niemand von ihm eine Frucht essen solle, heißt es in Mk 11, 21: ,... siehe, der Feigenbaum, den du verflucht

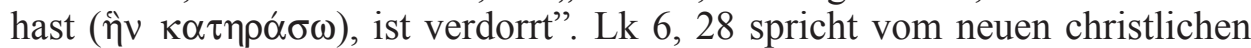

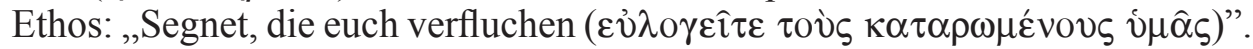
Nach Mt 25, 41 wird der Menschensohn beim Weltgericht zu denjenigen sagen, die auf der linken Seite stehen werden: „Gehet weg von mir, ihr Verfluchten

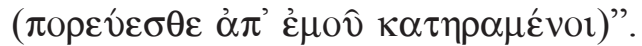

Aus all den angeführten Stellen ${ }^{62}$ ergibt sich, dass die in den Evangelien verwendeten Begriffe $\alpha \nu \alpha \theta \varepsilon \mu \alpha \tau i \zeta \omega$ und $\kappa \alpha \tau \alpha \rho \alpha ́ \alpha \mu \alpha \iota$ nur teilweise auf der Linie des paulinischen Anathems liegen. Sie gehören nämlich, wie es Doskocil überzeugend dargestellt hat, völlig zum jüdischen Bild von Fluch und Bann ${ }^{63}$, welches bei Paulus nur eine Nebenrolle spielt. Sowohl die evangelischen Termini als auch das paulinische $\alpha \dot{v} \alpha \dot{\alpha} \theta \varepsilon \mu \alpha$ knüpfen mit Sicherheit an die jüdische Idee der Vernichtung. Der größte Unterschied zwischen dem evangelischen und paulinischen Gebrauch der óvó́ $\theta \varepsilon \mu \alpha$-Begriffe besteht allerdings darin, dass Paulus sein Anathem eindeutig auf die Gegner Jesu und seines Evangeliums bezieht, während die Evangelisten den Terminus bzw. seine verbalen Formen in einem immer wechselnden Kontext verwenden. Denn die Stellen, die über die Selbstverfluchung des Petrus sowie über die Verfluchung des Feigenbaums durch Jesus, oder, die über den Aufruf zum Segen derjenigen, die verfluchen, und schließlich die über das Gericht der Verfluchten in der Endzeit berichten, sind von ihrem Kontext her so sehr unterschiedlich, dass eine Vereinheitlichung des Personenkreises, auf den sich die Verfluchung bezieht, unmöglich erscheint.

${ }^{61}$ 'Avó $\theta \eta \mu \alpha$ begegnet nur einmal in Lk 21, 5 und bezeichnet ein Weihegeschenk in seiner ursprünglichen Bedeutung. Von einem Fluch kann hier keine Rede sein, vgl. Doskocil, Der Bann in der Urkirche, S. 27.

${ }^{62}$ Brun fügt zu den von mir zitierten Abschnitten noch die Stelle über das Schütteln des Staubes von den Füßen (Mt 10, 14; Mk 6, 11; Lk 10, 11) hinzu und meint, es handle sich hier um eine Maßnahme, die dem Fluche nahe kommt, siehe: Brun, Segen und Fluch, S. 91.

${ }^{63} \mathrm{Vgl}$. Doskocil, Der Bann in der Urkirche, S. $27 \mathrm{ff}$. 
Aus diesem Grunde muss man feststellen, dass die evangelischen Perikopen, wo die Termini $\alpha \dot{v} \alpha \theta \varepsilon \mu \alpha \tau i \zeta \omega$ und $\kappa \alpha \tau \alpha \rho \alpha ́ \alpha \mu \alpha \iota$ auftauchen, dem Gesamtbild des Anathems keine nennenswerten Züge hinzufügen.

Es gibt allerdings in den synoptischen Evangelien eine Stelle, die dem Kontext und dem Sinn des paulinischen $\alpha$ $\alpha \alpha ́ \theta \varepsilon \mu \alpha$ sehr nahe zu kommen scheint. Es handelt sich hier um die Perikope aus Mt 18, 6-7 und ihre Parallelen Mk 9, 42 sowie Lk 17, 1-2. Da sich die drei genannten Stellen voneinander sehr wenig unterscheiden, stütze ich mich bei ihrer semantischen sowie theologischen Analyse prinzipiell auf Mt 18, 6-9.

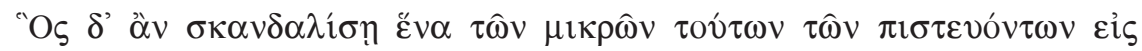

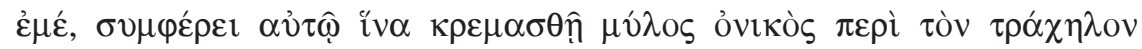

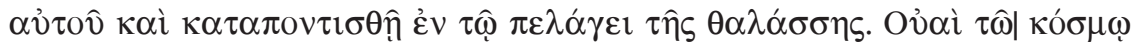

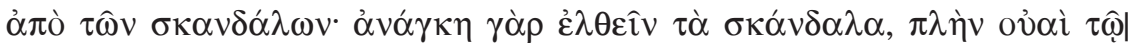

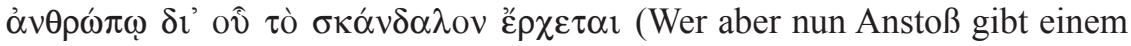
einzigen dieser Kleinen, die an mich glauben, dem ist es angemessen, dass der Mühlstein um seinen Hals gehängt wird und er versenkt wird in die Tiefe des Sees. Wehe der Welt wegen der Anstöße; denn es besteht die Notwendigkeit, dass die Anstöße kommen; aber wehe dem Menschen, durch den der Anstoß kommt) ${ }^{64}$.

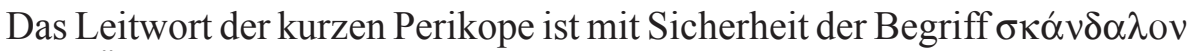
(Anstoß, Ärgernis). Der Evangelist verwendet diesen Terminus für Verführung und Abfall der Glaubensbrüder in der Gemeinde ${ }^{65}$. Diejenigen, die im Text als $\mu$ ıкрó́ (die Kleinen) genannt werden, „sind zwar gläubig, aber doch im Glauben gefährdet und für Verwirrung anfällig" ${ }^{\prime 6}$. Wer diese hilflosen Menschen zum Abfall von Christus bringt, wer sie verführt, indem er bei ihnen Anstoß erregt, der soll vernichtet werden. Die Formulierung „,der Mühlstein wird um seinen Hals gehängt und er wird versenkt in die Tiefe des Sees" weist ausdrücklich auf die Härte der Strafe hin, die ein Verführer verdient. Der Mühlstein, der ein sehr schweres Gewicht symbolisiert ${ }^{67}$, unterstreicht eindeutig die Größe und den Ernst des Vergehens, welches ein Mensch begeht, der andere zum Fall im Glauben bringt. Er soll in die Tiefe des Meeres verbannt werden, um dort für immer und endgültig vernichtet zu werden. Der Ausdruck „die Tiefe des Meeres” steht hier für den Aufenthaltsort der Dämonen ${ }^{68}$ und betont mit aller Eindringlichkeit die Zugehörigkeit des Verführers zum gottesfeindlichen Bereich. In dieser furchtbaren Schicksalsbestimmung derjenigen, die andere zum Abfall vom Glauben bringen, artikuliert sich bereits ihre

${ }^{64}$ Die Übersetzung stützt sich vorwiegend auf die Übertragung von A. Sand, Das Evangelium nach Matthäus, Regensburg 1986, 367.

${ }^{65}$ Vgl. ibidem, S. 368.

${ }^{66}$ S. Légasse, Mikros, Exegetisches Wörterbuch zum Neuen Testament II (1981) 1051.

${ }^{67}$ Zur Symbolik des Mühlsteines in dieser Perikope siehe Sand, Das Evangelium nach Matthäus, S. 368.

${ }^{68}$ Vgl. ibidem, S. 368. 
Verfluchung. Pesch sieht in dem Bild von der Meerestiefe einen Hinweis auf die Exkommunikation derer, die Ärgernisse sind ${ }^{69}$. Von einer Exkommunikation spricht aber der Text nicht. Er weist vielmehr auf die endgültige Vernichtung der Verführer hin und kommt damit dem Kontext der Begriffe „Anathem” sowie „Antichrist” sehr nahe. So wie der Anathematisierte und der Antichrist wird der Verführer für immer beseitigt werden; er gehört, genauso wie die beiden ersten, der dämonischen Sphäre an, weil er sich für die Verbreitung des Bösen einsetzt. Deshalb kann und muss er als verflucht gelten. Diese Tatsache betont noch der Wehe-Ruf, der gegen den Verführer gerichtet ist. Dieser Ruf unterstreicht ebenso mit aller Deutlichkeit, dass es kaum größeres Vergehen geben kann, als die Menschen vom Glauben abzulenken und sie in die Irre zu führen.

Zusammenfassend lässt sich mit einiger Sicherheit sagen, dass „der Verführer" aus dem Matthäusevangelium und ,der Anathematisierte” sowie ,der Antichrist" inhaltlich gleichzusetzen sind und sich auf denselben Menschenkreis beziehen. Hartnäckigkeit, Verbreitung einer antichristlichen Einstellung, endgültige Vernichtung stellen Begriffe dar, die mit jeder der genannten Personen in enger Verbindung stehen. Die Termini „Anathem”, „Antichrist" und „Verführer" verweisen demzufolge auf eine ernst zu nehmende Realität, die grundsätzlich gegen Christus und damit gegen die Christen ausgerichtet ist.

In der Literatur wird es häufig im Zusammenhang mit der Problematik der Exkommunikation auf die Perikope aus Mt 18, 15-17 hingewiesen, wo von der dreimaligen Zurechtweisung des Sünders sowie von seiner Ausschließung aus der Gemeinde die Rede ist. Doskocil reiht diese Stelle zusammen mit den

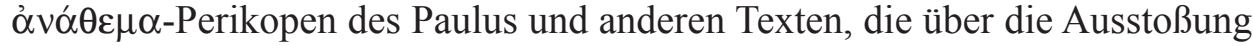
aus der Kirche berichten, in eine und dieselbe Gruppe ein. Mt 18, 15-17 hat aber kaum etwas mit der Frage des Anathems zu tun. Das zentrale Thema dieser Stelle ist eindeutig Sünde in der Gemeinde. Der Text spricht davon, dass der Sünder, der sich trotzt der Zurechtweisung vonseiten seiner Glaubensbrüder sowie schließlich der Kirche von seiner Sünde nicht abwenden will, als ,der Heidnische und der Zöllner" (Mt 18, 17b) zu betrachten ist. Er soll außerhalb der Gemeinschaft stehen. Möchte man nun diese Perikope mit der gerade dargestellten Stelle Mt 18, 6-7 vergleichen, so muss man feststellen, dass das Thema der Verführung und das Thema der Sünde vom Evangelisten völlig anders behandelt werden. Während Matthäus den Verführer der Gemeinde in die Tiefe des Meeres versenken lässt, nennt er den unbußfertigen Sünder als Heiden und Zöllner; während er von einer dreimaligen Zurechtweisung des Sünders spricht, legt er dem Verführer einen Mühlstein um den Hals. Die Schärfe der Ausdrucksweise, die der Verfasser auf den Verführer bezieht, ist deutlich größer als die, die den Sünder betrifft. Der Verführer soll endgültig vernichtet werden,

${ }^{69}$ Vgl. R. Pesch, Synopse nach Matthäus, Zürich - Einsiedeln - Köln 1980, 27. 
der Sünder soll von der Gemeinschaft der Gläubigen getrennt werden. Eine solche Gegenüberstellung macht deutlich, dass der Verführer, der aufgrund der Analyse von Mt 18, 6-7 durchaus mit dem Anathematisierten und dem Antichrist identifiziert werden kann, eine viel größere Gefahr als der Sünder darstellte. Dem ersten galt nämlich der Fluch, dem zweiten der Ausschluss aus der Gemeinschaft. Die Tatsache, dass der Evangelist das Thema Verführung und das Thema Sünde getrennt behandelt, bestätigt noch die These vom prinzipiellen Unterschied zwischen der neutestamentlichen „Exkommunikation” und dem neutestamentlichen „Anathem”. Aus diesem Grunde erscheint mir der Versuch, Mt 18, 15-17 mit den óvó́ $\theta \varepsilon \mu \alpha$-Stellen sowie anderen Texten, die inhaltlich dem Anathem nahe kommen, in Verbindung zu bringen, als verfehlt. Die Behauptung, das Anathem und sein Vorstellungsbereich seien mit dem Ausschluss aus der Gemeinschaft im Neuen Testament gleichbedeutend, entspricht nämlich der neutestamentlichen Praxis nicht und scheint, an der Differenz der ganzen Problematik vorbeizusehen.

\section{$* * *$}

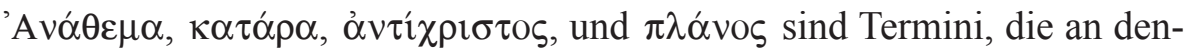
selben Vorstellungsbereich gebunden zu sein scheinen. All diese Begriffe werden im Neuen Testament im Bezug auf Personen verwendet, welche sich bewusst und definitiv entschieden haben, gegen Gott und seine Lehre zu kämpfen. Die Analyse der entsprechenden Stellen, an denen die genannten Ausdrücke zur Sprache kommen, ließ feststellen, dass der Einsatz dieser Begriffe auf ein zweifaches Kriterium zurückgeht. Nur in dem Fall, wo jemand hartnäckig und aktiv eine antichristliche Lehre oder Verhaltensweise verbreitet, andere zum Abfall von Christus bringt und Anhänger sucht, werden die von mir untersuchten Termini gebraucht. Es ist allerdings zu beachten, dass es sich hier um keine kirchenrechtliche, disziplinarische Sanktion handelt, die etwa mit der heutigen Exkommunikation gleichzusetzen wäre. Das Anathem und seine Synonyme wollen nämlich vielmehr der Bewahrung der Gemeinde vor den Pseudopropheten dienen, sie wollen Klarheit schaffen und eine Grenzlinie festlegen zwischen dem, was Wahrheit und Lüge ist. Die Anathematisierten gelten als verflucht, d.h. der Vernichtung durch Gott preisgegeben. Sie haben grundsätzlich kein Interesse an ihrer Bekehrung. An keiner der neutestamentlichen Stellen, die mit der Anathemproblematik verbunden sind, ist von der Hoffnung auf die Umkehr des Betroffenen die Rede. Aus diesem Grunde ist es verfehlt, vom Anathem als von einer Bußpraxis zu sprechen. Eine Einreihung der ỏvó $\theta \varepsilon \mu \alpha$-Stellen in eine Gruppe mit den Texten, die über den Ausschluss aus der Kirchengemeinschaft berichten, erscheint ebenso falsch. Denn eine undifferenzierte Betrachtungsweise sieht an der Tatsache vorbei, dass das Anathem und die Exkommunikation im Neuen Testament keineswegs gleichermaßen eingesetzt wurden. Das eine bezeich- 
nete die völlige Scheidung von Christus, „den seelischen Tod"70, das andere war eine Art Buße und zielte vor allem auf die Bekehrung des Betroffenen. Die Vielzahl der Termini, die das neutestamentliche Anathem zum Ausdruck bringen können, bezeugt allerdings, dass es noch keine feste Begrifflichkeit entstanden ist, sodass die Formulierungen, je nach Verfasser, variieren. Diese Tatsache ist wichtig für die weitere Analyse des Problems. Man darf nämlich bei der Behandlung der nachneutestamentlichen Quellen keine bereits fertige Anathematisierungspraxis mit allen institutionellen Umrissen erwarten. In diesem Zusammenhang erhebt sich die prinzipielle Frage, wie man nun bei der Untersuchung der frühkirchlichen Anathemproblematik vorgehen soll. Was muss unter die Lupe genommen werden, wenn eine feste Begrifflichkeit nicht $\mathrm{zu}$ erwarten ist? Die neutestamentliche Analyse scheint, eine gute Antwort auf diese Frage zu geben. Es wurde nämlich festgestellt, dass sich das Anathem im Neuen Testament an zwei Kriterien orientiert: dem Kriterium „der Hartnäckigkeit” und dem Kriterium „des aktiven Engagements bei der Verbreitung einer antichristlichen Einstellung". Diese zwei Kriterien geben der weiteren Analyse der Frage des Anathems eine gewisse Richtung. Möchte man nämlich die genannten Kriterien auf eine Personengruppe übertragen, so wird man in erster Linie auf die Häretiker hingewiesen, deren Aktivität ja ex definitione auf die programmatische sowie hartnäckige Verbreitung einer mit dem einen Evangelium Christi im Widerspruch stehenden Botschaft eingestellt ausgerichtet ist. Deshalb soll man bei der Untersuchung der frühkirchlichen Anathemproblematik zunächst der Frage nachgehen, wie die Kirche mit den Irrlehrern umgegangen ist. Gab es in diesem Aspekt eine einheitliche Vorgehensweise? Oder variierte die Praxis je nach der Region? Kann man überhaupt von Anathematisierungen in der Zeit der Apostolischen Väter sprechen? Auf diese Fragen will das nächste Kapitel eingehen.

Fortsetzung folgt

\section{ANATEMA W NOWYM TESTAMENCIE}

\section{(Streszczenie)}

Grecki termin ỏvó́ $\theta \varepsilon \mu \alpha$, oznaczający rzecz lub osobę przeklętą, pojawia się w Nowym Testamencie jedynie u św. Pawła. Apostoł używa tego słowa, jako określenia odnoszącego się do rzeczywistości obejmującej działania wymierzone przeciwko zbawczej misji Chrystusa i dotyczące tym samym obszaru związanego $\mathrm{z}$ aktywnością Szatana. Pawłowa anatema rozciąga się w związku z tym na tych ludzi, którzy, podobnie jak Zły Duch, dążą do odebrania Chrystusowi wyznawców i sprowadzenia ich na drogę walki ze Zbawicielem. Nie odnosi się ona zatem

${ }^{70}$ Hofmann, Anathema, S. 429. 
do „zwykłych” grzeszników, którzy powodowani ludzką słabością upadają, aby później korzystając z miłosierdzia Bożego powracać do stanu łaski. Anatema św. Pawła dotyka zatem tych, którzy w sposób świadomy i zatwardziały angażują się w rozprzestrzenianie antychrześcijańskich zachowań bądź nauk i tym samym włączają się w czynną i programową walkę z Chrystusem. Owo podwójne kryterium zatwardziałości i aktywnego zaangażowania w pozyskiwaniu zwolenników dla wrogich doktrynie chrześcijańskiej poglądów jest charakterystycznym wyznacznikiem zastosowania anatemy przez Apostoła i zwraca uwagę na to, że objęty anatemą jest fałszywym prorokiem i znajduje się w obszarze podległym Szatanowi, który potrafi niekiedy przybierać postać Anioła Światła po to, aby zwodzić wierzących (por. 2Kor 11, 14). Anatema staje się w tym kontekście dla chrześcijan niezwykle ważną pomocą, pozwalającą łatwo i niezawodnie odróżnić naukę Chrystusa od wywodzącej się z szatańskiej inspiracji doktryny fałszu. Anatema stanowi jasną linię, wyznaczającą granicę między prawdą a kłamstwem. Jest zatem czymś zasadniczo różnym od ekskomuniki, która w Nowym Testamencie odnosi się przede wszystkim do grzeszników i ma na celu, przez czasowe wyłączenie ich z życia wspólnoty, dać im możliwość pokuty za popełnione winy i powrotu do nieskazitelności dzieci Bożych. Anatema zakłada natomiast daleko posuniętą zatwardziałość objętego nią człowieka, który, podobnie jak Szatan, nie jest zainteresowany swoim nawróceniem. Podobne znaczenie, co Pawłowa anatema, mają również pojawiające się u innych nowotestamentalnych autorów terminy takie

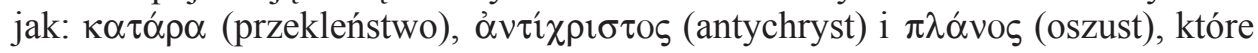
zakładają, że objęta nimi osoba jest apostołem Szatana i tym samym znajduje się w przeklętej sferze fałszu. Terminologiczna różnorodność określeń wchodzących znaczeniowo w obszar używanego przez św. Pawła słowa anatema dowodzi, że w okresie powstawania pism Nowego Testamentu nie wytworzyła się jeszcze jednoznaczna nomenklatura związana $\mathrm{z}$ praktyką anatematyzowania. $Z$ drugiej jednak strony jest ona bardzo wczesnym świadectwem konieczności posługiwania się terminami funkcjonującymi, jako pewnego rodzaju znaki ostrzegawcze, chroniące „tych najmniejszych” przed zepsutymi doktrynami fałszywych apostołów. 